\title{
Two-Stage Efficiency Structure Analysis Model of Shipbuilding Based on Driving Factors: The Case of Chinese Shipyard
}

\author{
Lei Xue', Guofu Shi' ${ }^{1}$, Dashuang Dai ${ }^{1}$, Yizhuang $\mathrm{Xu}^{2}$ \\ ${ }^{1}$ School of Management and Economics, Dalian University of Technology, Dalian, China \\ ${ }^{2}$ Audit Division, Dalian Shipbuilding Industry Co., Ltd., Dalian, China \\ Email: thunder_xue@126.com,1272734025@qq.com,daids@dlut.edu.cn,67822272@qq.com
}

How to cite this paper: Xue, L., Shi, G. F., Dai, D. S., \& Xu, Y. Z. (2020). Two-Stage Efficiency Structure Analysis Model of Shipbuilding Based on Driving Factors: The Case of Chinese Shipyard. Open Journal of Social Sciences, 8, 182-200.

https://doi.org/10.4236/jss.2020.82015

Received: December 21, 2019

Accepted: February 25, 2020

Published: February 28, 2020

Copyright $\odot 2020$ by author(s) and Scientific Research Publishing Inc. This work is licensed under the Creative Commons Attribution International License (CC BY 4.0).

http://creativecommons.org/licenses/by/4.0/

\begin{abstract}
The purpose of this paper is to build an efficiency evaluation model based on efficiency drivers. Building technique, resource ability and management level are the three main driving factors in production efficiency of shipbuilding. Two-stage internal production efficiency structure analysis model (ESAM) firstly decomposes the shipbuilding system efficiency into three dimensions of subsystem efficiency structures to express the driving effect of the three driving factors of technique, operation and management. Secondly, ESAM uses system efficiency function and dimension structure efficiency function to express the relationships between the efficiency of each level and its subordinate efficiency. The contribution of subsystems to system efficiency is represented by the regression coefficient while the driving relationship between the efficiency of the subsystems and the efficiency of the system is expressed by the moving average trend curves of the system efficiency and the structural efficiency of each dimension. The empirical analysis shows that the case shipyard inner production is inefficient, which implies that most Chinese shipyards may be in the same condition, or even worse. It also shows that operation efficiency has the greatest driving effect on shipbuilding system efficiency while the driving effect of technique efficiency is not obvious, which means that improving management efficiency and technique efficiency should be the main direction taken to improve Chinese shipbuilding efficiency.
\end{abstract}

\section{Keywords}

Evaluation Model, Production Efficiency, Shipbuilding Enterprises, Driving Factors 


\section{Introduction}

Though China has been the world's largest shipbuilding country since 2011, many research results show that there is still a big gap between China and other advanced shipbuilding countries in the facet of shipbuilding efficiency. Therefore, improving the overall efficiency is an urgent issue if the goal is to realize the sustainable development of China's shipbuilding industry (Jiang et al., 2013; Lee, 2013; Zhao et al., 2015; Liu et al., 2017).

Efficiency evaluation is the precondition and foundation of efficiency improvement. In terms of efficiency improvement, academia and Chinese shipbuilding enterprises have done a lot of theoretical research and practice verification on how to increase output and reduce costs. In terms of efficiency evaluation methods, most of them focus on the causes of efficiency differences among individual countries, industries, regions and enterprises. However, there is almost no research on evaluation methods combined with efficiency improvement effects.

When seeking improvement of shipbuilding efficiency, the existing research focused on three aspects. The first is to study how to minimize the quantities of jobs of shipbuilding by using technological means. To specify, this is to study how to improve shipbuilding efficiency by simplifying the production process. The second is to study how to maximize the efficiency of the production process, focusing on how to improve the efficiency of shipbuilding production by developing and applying advanced production technology and specialized production techniques. The third is to study how to minimize shipbuilding cost by way of management restructuring, such as how to shorten shipbuilding circle time, reduce shipbuilding costs overall and improve shipbuilding efficiency through management activities. These research results have played a significant role in improving the efficiency of shipbuilding in theory. But, how to quantify the effect of these methods has not been studied in the existing literature. In order to fill these gaps, this paper attempts to construct a new method for evaluating the improvement results for shipbuilding efficiency based on the current efficiency improvement methods used in the shipbuilding industry, focusing on job minimization, operation efficiency maximization, outputs maximization, cost minimization etc. The new method will be helpful in the decision making processes undertaken by the shipbuilding management in regards to increasing efficiency.

The main contributions of this paper are as following: 1) Construct the efficiency dimensional space and regression model of shipbuilding by introducing the production process, technique and organization as the dimensions; 2) use the regression coefficient of each subsystem to express the efficiency contribution of this subsystem to the system as a whole; 3) construct the efficiency measurement model based on the windows DEA (Data envelopment analysis) which is suitable for the systems with multi input and output dimensions and small number of samples; 4) construct a trend model of the system efficiency and of each dimension system function to embody the efficiency change with the effect of the efficiency driver. The other sections of this paper are arranged as follows: 
The second section reviews the existing research and introduces the modeling method of this paper. The third section constructs the efficiency structure analysis model. The forth section uses empirical analysis to look at shipyard efficiency using the efficiency structure analysis model and verify the validity of the model, followed by discussing the implications of the model. The fifth section is the conclusion and future prospects of this research.

\section{Literature Review}

Total Factor Productivity (TFP), Solow Residual, Stochastic Frontier Analysis (SFA), Data Envelopment Analysis (DEA) and the Malmquist TFP Index are the most popular efficiency evaluation methods in recent years. Many scholars have studied the applicability of these methods in various fields. Zheng (2007) thought that TFP was best used for studying short term economic efficiency of production factors, and that it was difficult to use to fully reflect the economic results of production factors, meaning that it makes it easy to underestimate the importance of capital accumulation. Duan \& Yin (2009) and Felipe (1999) thought that the strict constant returns to scale and Hicks neutrality assumptions limited the application of Solow Residual in the systems with variable scale returns and technological progress bias. Cheng et al. (2018) believed that the stochastic frontier function must strictly abide by the default function in the form and the statistics of the distribution of non efficiency, and this method was only applicable to the system with one output, not suitable for the system whose production function was not fixed or for a system with multi outputs.

DEA was once thought of as one of the most suitable efficiency evaluation methods of production systems involving multi inputs and outputs. In combination with the Malmquist TFP index, DEA can be used not only to evaluate the relative efficiency of a set of similar decision making units, but also to measure the efficiency changes caused by the four possible ways of technique change, the technological efficiency change, the return to scale and the TFP change. Many scholars had developed many new evaluation models by combining these two methods with Stochastic Frontier Function, Grey Relational Analysis and Analytic Hierarchy Process, showing the strong advantage of DEA in evaluating production efficiency. In particular, the emergence of the network DEA model provided the possibility of evaluating the efficiency relationship among subsystems within a complex system. Tsaur et al. (2017) studied the performance evaluation of Taiwan TFT-LED industry using DEA; Wang et al. (2010) studied the application of DEA and grey relational analysis to measure production efficiency and marketing efficiency; Joo \& Choi (2015) researched the management performance of different products between different products and production lines based on DEA method; Lee (2012) applied DEA and Malmquist index method to calculate the production efficiency of some shipyards of Korean small and medium-sized shipyards; Chudasama (2010) applied the DEA method to calculate the production efficiency of some of India's shipyards; Donghyun Oh 
(2014) studied the difference of total factor productivity between individuals of Korean manufacturing enterprises. Almost all of these studies took the production organization as the evaluation object and took the technical change, technical efficiency change, scale efficiency change and total factor productivity change as the sources of efficiency improvement. As well they all used the AHP method, gray correlation analysis and so on to analyze the relations between the system and the driving factors of change. The production technology, knowledge, investment and scale of production were taken as the driving factors of efficiency in these studies, which almost cannot be directly related to the efficiency improvement measures taken by shipbuilding enterprises.

The research on improving the efficiency of shipbuilding has shown that building technique, resource ability and management level were the main driving factors for improving the efficiency of shipbuilding. Gallagher et al. (1974) introduced Group Technology into the shipbuilding industry, Jin et al. (2002) proposed a more modern shipbuilding work breakdown structure, Zhong et al. (2004) and Chen (2002) proposed the modular design method. They were all try to improve production efficiency by optimizing the process method via reducing the workload or lowing the difficulty of construction. Ku et al. (2014) and Liu (2011) proposed modern automatic welding technology, three-dimensional positioning technology etc. for use in the shipbuilding industry, and Zhong et al. (2014) proposed to classify intermediate products for specialized production to improve efficiency by using the group technology and cluster analysis technology. They all tried to improve the shipbuilding efficiency by enhancing the ability of resources. The cost (man hour) control models developed by Niksa Fafandjel et al. (2010) and Emblemsvag (2014) etc. created studies that contributed to the work of Hassan \& Kajiwara (2013); and studies on the running distance optimization of the crane were done by Roh \& Lee (2010) etc. They aimed to apply the lean production and operational research methods in shipbuilding production management by achieving balancing production via means of management, reducing the waste of resources, and shortening the shipbuilding cycle time of product construction to achieve efficiency improvement.

Combined with the research results of these shipbuilding efficiency improvement methods, this paper put technique, operation and management as the efficiency driving factors into the shipbuilding efficiency evaluation model. By decomposing the shipbuilding efficiency into product efficiency, operation efficiency and management efficiency, and further decomposing product efficiency into technique efficiency and product operation efficiency, we can use the technique, operation and management efficiency to reflect the driving effect of the three factors of shipbuilding efficiency

\section{Methodologies}

\subsection{Framework of ESAM}

ESAM composes three sub models of two phases, as shown in Figure 1. In the 


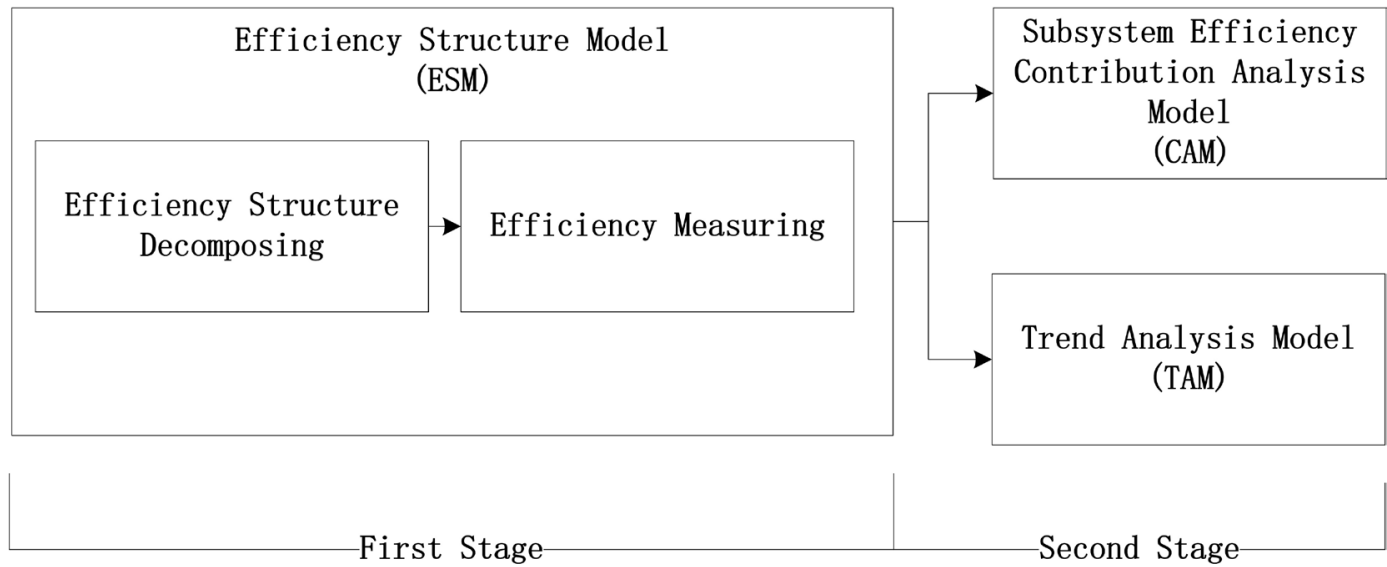

Figure 1. Two stage efficiency structure analysis model (ESAM).

first stage of the model, the shipbuilding efficiency is decomposed and measured which is done by the efficiency structure decomposition and measurement sub model (ESM). In the second stage of model, the contribution of the subsystem efficiency to the system efficiency and the change trend of varied efficiencies are analyzed which is done by the analysis sub model of contribution rate of structural efficiency (CAM) and analysis sub model of change trend of structural efficiency (TAM).

\subsection{Efficiency Structure Sub Model (ESM)}

\section{1) System efficiency structure}

Efficiency is term used to characterize the performance of a system in regards to its input and output. For the complex product system of shipbuilding, it can be decomposed into several subsystems and expressed in a production set. Suppose $S$ is the shipbuilding system; $S$ can be decomposed into $m$ levels and $n$ subsystems of each level; $S_{i j}$ is the $i$ level $j$ subsystem of; $\boldsymbol{X}_{i j}, \boldsymbol{Y}_{i j}$ is the input and output vector of the subsystem $S_{i j}$, then the relationship between the shipbuilding production system and its subsystems can be expressed as:

$$
\begin{gathered}
S=\left\{S_{i j} \mid i=1,2, \cdots, m ; j=1,2, \cdots, n\right\} \\
S_{i j}=\left\{\boldsymbol{X}_{i j}, \boldsymbol{Y}_{i j} \mid S_{i j} \text { using } \boldsymbol{X}_{i j} \text { to produce } \boldsymbol{Y}_{i j}\right\}
\end{gathered}
$$

The efficiency of the system can be represented by the efficiency of the decomposed subsystems. System efficiency is the comprehensive embodiment of the efficiency of all secondary subsystems, while the efficiency of the subsystem is the microscopic performance of system efficiency as a whole. This paper names this form of efficiency set of subsystems as the efficiency structure of the system. In relation, it names the efficiency of the subsystems in the system efficiency structure as the internal structure efficiency of the shipbuilding system. This paper also expresses the relationship between system efficiency and internal structure efficiency by the system efficiency function. Suppose $E_{i}$ is the efficiency of shipbuilding system $S_{i}, E_{i i}$ is the efficiency of subsystem $S_{i j}$ of 
$S_{i}$, then the system efficiency function is:

$$
E_{i}=f\left\{E_{i j} \mid i=1,2, \cdots, m ; j=1,2, \cdots, n\right\}
$$

In order to measure the effect of the driving factors of efficiency, this paper decomposes the shipbuilding production system from the three dimensions of product structure, process structure and production organization structure into a number of levels with a number of subsystems as shown in Figure 2(a), and names the efficiency of the subsystems in each dimension as product efficiency, operation efficiency and management efficiency, respectively. The system efficiency refers to the utilization of the production system to its production resources, and is the comprehensive embodiment of all product efficiency, operation efficiency and management efficiency in the system as a whole. Operation efficiency refers to the extent to which the ability to produce resources is used. Product efficiency refers to the extent of the product's consumption of resources. Product efficiency can also be decomposed into operation efficiency of all the process applied on this product plus technique efficiency. The operation efficiency
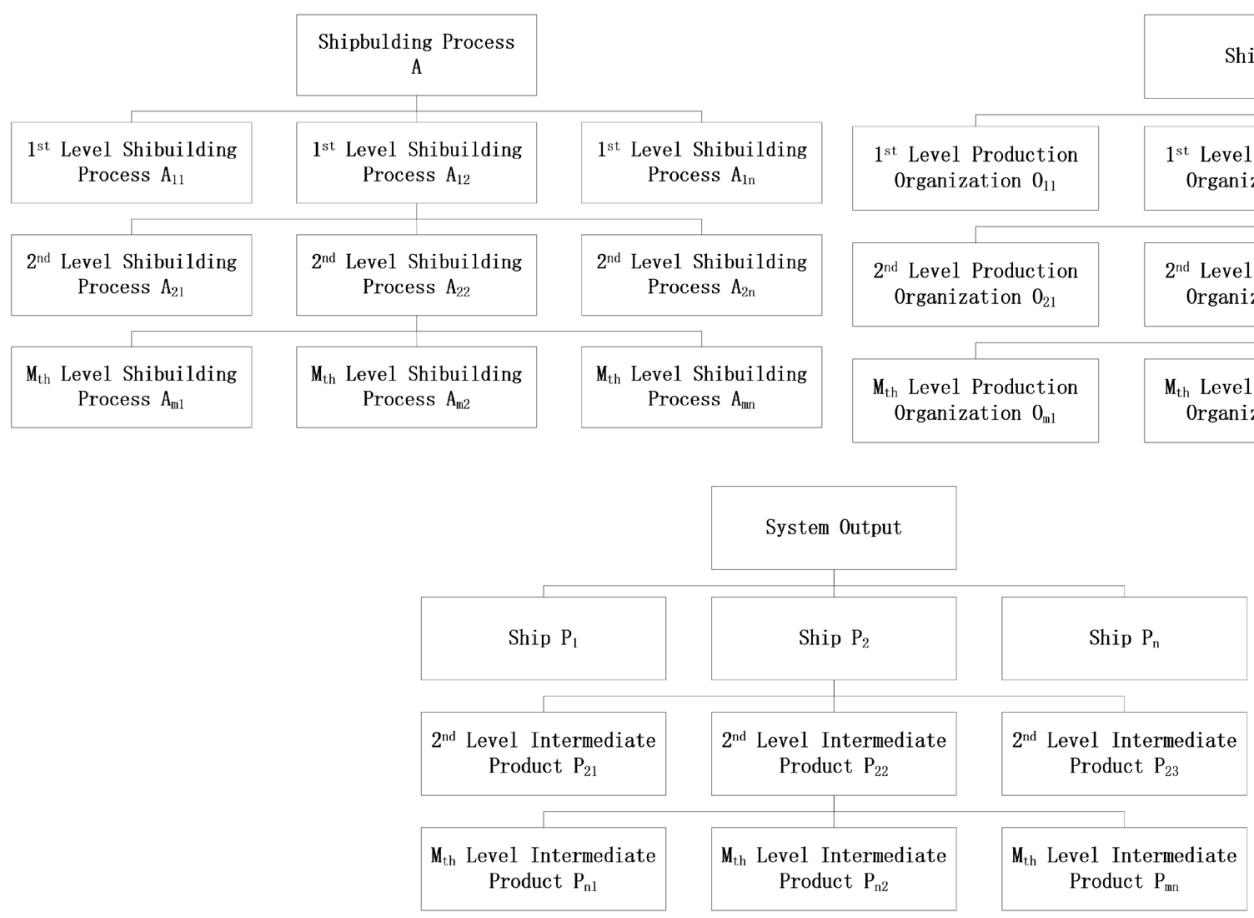

(a)

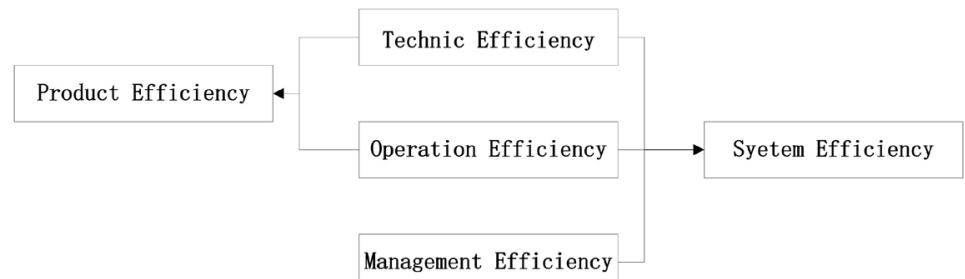

(b)

Figure 2. The dimension decomposition of the production system. 
of the product refers to the exertion degree of production resources capacity applied to the product, while the technique efficiency refers to the reduction degree of process technique to the consumption of product resources. Management efficiency refers to the reduction degree of idle resource and the increasing degree of the technique efficiency and operation efficiency in the production organization. The relationship between the four elements of system efficiency, product efficiency, operation efficiency and operational efficiency is shown in Figure 2(b).

The system efficiency can be calculated by the system efficiency function. Suppose $E, E_{P}, E_{A}, E_{O}$ and $E_{T}$ are the variables of system efficiency, product efficiency, operation efficiency, management efficiency and technique efficiency, then the efficiency function of each dimension can be expressed in the form of formula (3); the efficiency function of the system can be expressed in formula (4):

$$
\begin{aligned}
& E=f\left(E_{T}, E_{A}, E_{O}\right) \\
& E_{T}=E_{P}-E_{A}
\end{aligned}
$$

\section{2) Efficiency dimension space}

The efficiency of the system and the efficiency of subsystems of the three dimensions constitute the efficiency space as shown in Figure 3. The three axes indicate the technique efficiency, the operation efficiency and the management efficiency respectively. The efficiency of subsystems in three dimensions can play an independent role in the efficiency of the system as a whole. Two or three of these subsystems can affect the efficiency of the whole system. Any straight line parallel to a coordinate axis in the efficiency dimension space represents the efficiency set of the efficiency dimension, and it also indicates contribution to system efficiency under the condition that the efficiency set of the other two dimensions is invariable. In the efficiency space, any plane parallel to the coordinate axis indicates joint contribution to the system efficiency of the two dimensions of subsystem efficiency set in the case that the third dimension efficiency

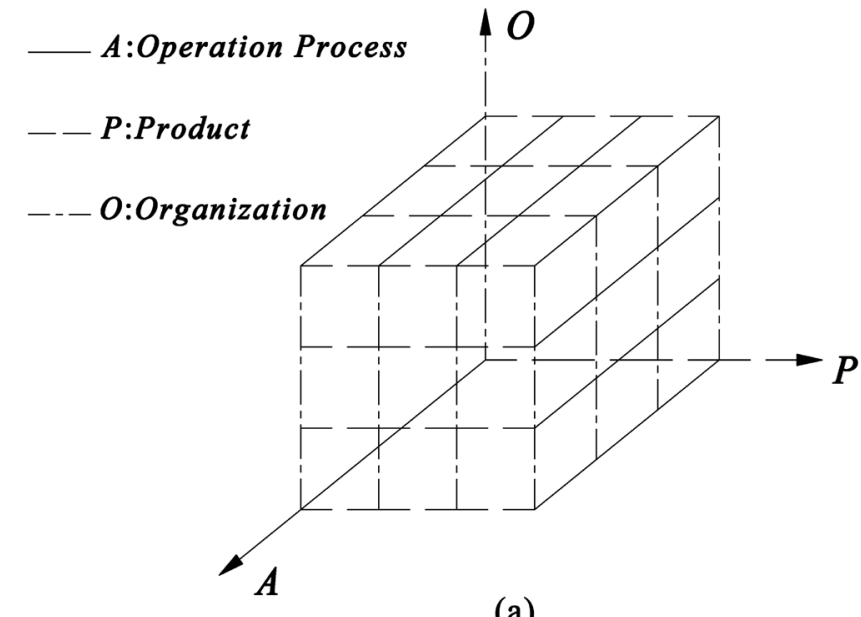

(a)

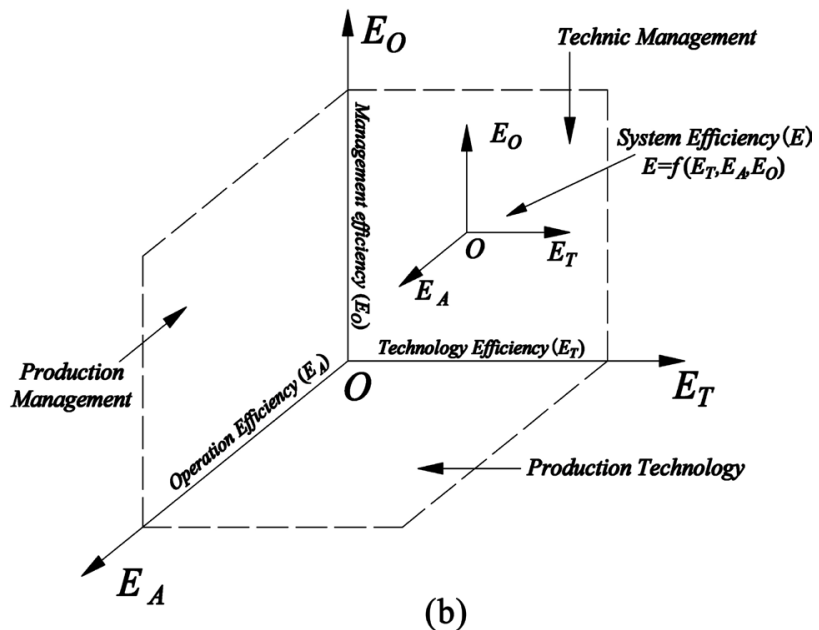

(b)

Figure 3. Efficiency dimension space. 
set of the subsystems is constant. In this paper, three groups of planes parallel to the coordinate axis are called the production management plane, the technique management plane and the production technique plane respectively. Collectively they are referred to as the two dimensional joint efficiency plane, and they represent the system efficiency driving space by any two dimensions of management, technique and process. Any point in the efficiency space is the common effect of the three dimensions of the subsystem efficiency set on the efficiency of the system.

\section{3) Efficiency algorithm}

In the decomposed shipbuilding sub system, many of these systems are multi input and multi output. Also, the dimensions of the input and output may be different. In addition, the shipbuilding cycle time is longer and the number of samples is fever. In order to overcome these difficulties, window DEA was chosen as the computing tool for the shipbuilding sub systems.

\section{a) Algorithm of system efficiency, product efficiency and operation effi- ciency}

Suppose $S_{j}(j=1,2, \cdots, t)$ is a decision making unit $(D M U)$ at $j$ period, $\theta^{j}$ is the efficiency of $S_{j}$, which using $m$ kind of inputs $X\left(x_{i}=1,2, \cdots, m\right)$, produces $q$ kind of outputs $Y\left(y_{i}=1,2, \cdots, q\right)$. Thus, the efficiency $\theta^{j}$ of the system $S_{j}$ and its dimension efficiency of $E_{A}$ and $E_{P} \mathrm{c}$ of $S_{j}$ can be computed by the input-oriented, varied return to scale BCC model proposed by Banker \& Charnes (1984):

$$
\begin{gathered}
\theta^{j}=\min \sum_{i=1}^{m} v_{i} x_{i k}+v_{0} \\
\text { s.t. } \sum_{r=1}^{q} u_{r} y_{r i}-\sum_{i=1}^{m} v_{i} x_{i j}-v_{0} \leq 0 \\
\sum_{r=1}^{q} u_{r} y_{r k}=1 \\
v \geq 0 ; \quad u \geq 0 ; \quad v_{0} \quad \text { Free } \\
i=1,2, \cdots, m ; \quad r=1,2, \cdots, q ; j=1,2, \cdots, t
\end{gathered}
$$

The above model can also be computed by the optimal solution of the dual programming as shown in the model (7):

$$
\begin{gathered}
\theta^{j}=\min \phi \\
\text { s.t. } \sum_{j=1}^{t} \lambda_{j} x_{i j} \leq x_{i k} \\
\sum_{j=1}^{t} \lambda_{j} y_{r j} \geq \phi y_{r k} \\
\sum_{j=1}^{t} \lambda_{j}=1 \\
\lambda \geq 0
\end{gathered}
$$




$$
i=1,2, \cdots, m ; r=1,2, \cdots, q ; j=1,2, \cdots, t
$$

\section{b) Algorithm of management efficiency}

For management efficiency, this paper uses the two stage algorithm, which is to calculate the management inefficiency first and then convert it to the management efficiency. Suppose $E_{O}^{\prime}, E_{A}^{\prime}, E_{P}^{\prime}$ as the management inefficiency, operation inefficiency, product inefficiency, and $E_{A}^{\prime}, E_{P}^{\prime}$ and the idle resources $W$ as the output, and the indirect production resource such as managers, engineers etc. as the input of the sub systems of organization dimension. Thus, the management efficiency can be computed by the formula (7)

$$
\begin{aligned}
& E_{A}^{\prime}=1-E_{A} \\
& E_{P}^{\prime}=1-E_{P} \\
& E_{O}=1-E_{O}^{\prime}
\end{aligned}
$$

\section{4) Input and output variables of sub shipbuilding systems}

The input and output of the subsystems mentioned above are not only different but also connected. If the set $X$ and set $Y$ represent the input and output of system efficiency, sets $X_{p}, X_{a}, X_{o}$ and sets $Y_{p}, Y_{a}, Y_{o}$ respectively represent the input and output of product structure system, operation structure system and organization structure system. With that in mind, then the input and output sets of the shipbuilding system is the sums of the input and output of the three dimensions of structure systems, so $X=X_{p}+X_{a}+X_{o}, X=X_{p}+X_{a}+X_{o}$. The input of $X_{o}$ is the equipment and facilities of non production and staff of non production, the output $Y_{o}$ is defined as the inefficiency of techniques, the inefficiency of operation and idle production resources. There is some crossover between input and output of the operation structure system and the organization structure system, because the same operation will be used on different products, and the same product has one or several operations to complete.

According to the current shipbuilding model used in Chinese shipbuilding enterprises, we choose 7 inputs and 8 outputs as shown in Table 1 as input and output variables of two kinds of production systems for products and operations.

\subsection{Efficiency Structure Analysis Sub Model}

\section{1) Efficiency contribution analysis sub model (CAM)}

The efficiency of the system and its subsystems at all levels can be computed through its input and output calculations. The expression of system efficiency

\begin{tabular}{|c|c|c|c|c|c|c|c|c|c|c|c|c|c|}
\hline \multicolumn{7}{|c|}{ Input $X$} & \multicolumn{7}{|c|}{ Output $Y$} \\
\hline labor & Dock & $\begin{array}{l}\text { Lifting } \\
\text { facility }\end{array}$ & $\begin{array}{c}\text { Pre-erection } \\
\text { area }\end{array}$ & $\begin{array}{c}\text { Blocks } \\
\text { assembly } \\
\text { area }\end{array}$ & $\begin{array}{l}\text { Erection } \\
\text { crane }\end{array}$ & $\begin{array}{c}\text { Steel } \\
\text { cutting } \\
\text { facility }\end{array}$ & $\begin{array}{c}\text { Mooring } \\
\text { testing } \\
\text { vessel }\end{array}$ & $\begin{array}{c}\text { General } \\
\text { assembly } \\
\text { vessel }\end{array}$ & $\begin{array}{l}\text { Pre-erection } \\
\text { blocks }\end{array}$ & Blocks & Model & Assembly & Parts \\
\hline$X_{1}$ & $X_{2}$ & $X_{3}$ & $X_{4}$ & $X_{5}$ & $X_{6}$ & $X_{7}$ & $Y_{1}$ & $Y_{2}$ & $Y_{3}$ & $Y_{4}$ & $Y_{5}$ & $Y_{6}$ & $Y_{7}$ \\
\hline
\end{tabular}
function and dimension efficiency function can be solved by using the standard multiple regression model of formula (5). This paper names it as a contribution

Table 1. Variables of input \& output of general assembly shipbuilding system. 
of subsystem efficiency to the efficiency of the system. $\beta_{0}$ is the initial value of system efficiency when all subsystem efficiency is 0 .

$$
E=\beta_{0}+\beta_{1} E_{1}+\beta_{2} E_{2}+\cdots+\beta_{k} E_{k}+\varepsilon
$$

The regression coefficient $\beta_{k}$ in the formula refers to the change in the efficiency $E$ of the system when the efficiency of other subsystems is constant and the efficiency $E_{k}$ of the subsystem $S_{k}$ is changed per unit. $\varepsilon$ is a random error. Thus, the efficiency of the system and the efficiency of the dimension can be represented as:

$$
\begin{gathered}
E=\beta_{0}+\beta_{P} E_{P}+\beta_{A} E_{A}+\beta_{O} E_{O}+\varepsilon \\
E_{P}=\beta_{P 0}+\beta_{P 1} E_{P 1}+\beta_{P 2} E_{P 2}+\cdots+\beta_{P k} E_{P k}+\varepsilon_{P} \\
E_{A}=\beta_{A 0}+\beta_{A 1} E_{A 1}+\beta_{A 2} E_{A 2}+\cdots+\beta_{A k} E_{A k}+\varepsilon_{A} \\
E_{O}=\beta_{O 0}+\beta_{O 1} E_{O 1}+\beta_{O 2} E_{O 2}+\cdots+\beta_{O k} E_{O k}+\varepsilon_{O}
\end{gathered}
$$

\section{2) Efficiency trend analysis sub model (TAM)}

The time trend of system efficiency, especially that of subsystems and their dimension, is an important way to analyze the effect of driving factors on efficiency. This paper takes the system efficiency and the subsystems efficiency of each dimension as dependent variables and takes time as an independent variable. A moving average model as shown in (11) is used to demonstrate some trend curves. By comparing the system efficiency with subsystems efficiency of each dimension and the efficiency of each dimension with the efficiency of its sub subsystem, the trend curve can be used to qualitatively analyze the interactive relationship between various efficiencies and to predict the trend of development.

$$
E_{t}=\frac{E_{t-1}+E_{t-2}+E_{t-3}+\cdots+E_{t-n}}{n}
$$

In (11), $E_{t}$ is the prediction efficiency value of the next phase, $n$ is the number of mobile average periods, and $E_{t-1}$ is the actual efficiency value of early stage. $E_{t-2}, E_{t-3}$ and $E_{t-n}$ represent the actual value of the first two periods and the first three periods until the early $n$ periods.

\section{Empirical Analyses}

\subsection{Case Brief Introduction}

In order to verify the effectiveness of the above efficiency structure evaluation model, we selected a Chinese shipbuilding enterprise as an example. From there we analyzed the hull erection of the core production process in the shipbuilding system. This Chinese shipbuilding enterprise is one of the largest state-owned shipbuilding companies in China, whose design level, management level and shipbuilding facilities basically represent the highest level in current Chinese shipbuilding enterprises. The data was taken from production data of one of the shipyards in the enterprise in the years 2012-2014.

During the time in 2012-2014, under the influence of the international financial crisis, the output of the company began to decline from its peak, production 
rhythm gradually slowed down; the utilization rate of production resources was seriously reduced. In order to improve the efficiency of production, many measures had been taken by the shipyard, such as increase the quantities of blocks in the pre-erecting stage and decrease the quantities of blocks in the erection stage; adjust the production plan of intermediate products frequently to reduce the idle resources; using the timing of the slowdown of the production, try to expand the scope of the implementation of the pre trimming of the segmented allowance using the three dimensional positioning technology. In spite of this, the efficiency of the shipyard in those three years was still falling, and the expected effect was not reached. Therefore, this paper tries to use the efficiency structure model to verify the internal structure efficiency of the workshop according to the following steps.

1) Construct the efficiency structure model

2) Select the input and output variables and collect data

3) Calculate the efficiency of system and subsystems of each dimension

4) Regress the system efficiency function and subsystems efficiency function of each dimension;

5) Nonlinear regression trend function of s efficiency of system and subsystems of each dimension, get the trend chart of efficiency changing with time;

6) Analyse and discuss the result obtained above according to the actual situation of the shipyard.

\subsection{Efficiency Structure}

The hull erection organization $S$ is decomposed into two departments, as shown in Figure 4, the pre-erection department $O_{1}$ and the erection department $O_{2}$. The production processes are divided into pre erection $A_{1}$ and erection $A_{2}$. The products of two departments of $O_{1}$ and $O_{2}$ are three types of pre-erected blocks $C_{1}, B_{1}, P_{1}$ and erected hull structure $C_{2}, B_{2}$ and $P_{2}$. Three types of blocks $C_{0}, B_{0}, P_{0}$ and labor $L_{21}$ are the inputs of $O_{1}$. Three types of pre-erected blocks, $C_{1}, B_{1}, P_{1}$ and labor $L_{21}$ are the inputs of $O_{2}$. The managers and staff of $L_{1}, L_{11}$ and $L_{12}$ are the management inputs for system $S$ and organization $O_{1}, O_{2}$; whereas the management outputs of the system $S$ and the organization $O_{1}, O_{2}$ are the idle resource $W, W_{1}$ and $W_{2}$, and the activity efficiency $E_{A}^{\prime}$ and product efficiency $E_{P}^{\prime}$.

Thus, in $J(j=1,2, t)$ period, the efficiency function of the $S_{j}$ can be expressed as:

$$
\begin{gathered}
E^{j}=\beta_{0}+\beta_{T} E_{T}^{j}+\beta_{a} E_{A}^{j}+\beta_{O} E_{O}^{j}+\varepsilon \\
E_{T}^{j}=\beta_{T 0}+\beta_{T 1} E_{T 1}^{j}+\beta_{T 2} E_{T 2}^{j}+\varepsilon_{T} \\
E_{A}^{j}=\beta_{A 0}+\beta_{A 1} E_{A 1}^{j}+\beta_{A 2} E_{A 2}^{j}+\varepsilon_{A} \\
E_{O}^{j}=\beta_{O 0}+\beta_{O 1} E_{O 1}^{j}+\beta_{O 2} E_{O 2}^{j}+\varepsilon_{O}
\end{gathered}
$$

\subsection{Variables of Input and Output}

The input and output variable data was taken from the production reports for 
the years 2012-2014 from the Chinese shipyard we used as an example. Inputs, outputs and variables are shown in Table 2. The window width of the DMU is set to 1 month, so we have the corresponding 36 DMUs of input and output data.

\subsection{Results}

By the window DEA model (8) built above, the system efficiency and 9 internal structure efficiencies was computed. The results are shown in Table 3. The calculation results of each variable in Table 3 were divided into four groups (system efficiency, the efficiency of three dimensions, efficiency of each dimension and sub systems), and the results of these four groups were polynomial regressed by the model (12)-(15) with time as the invariable factor. The corresponding efficiency functions were obtained as shown in formula (16)-(19) and the trend

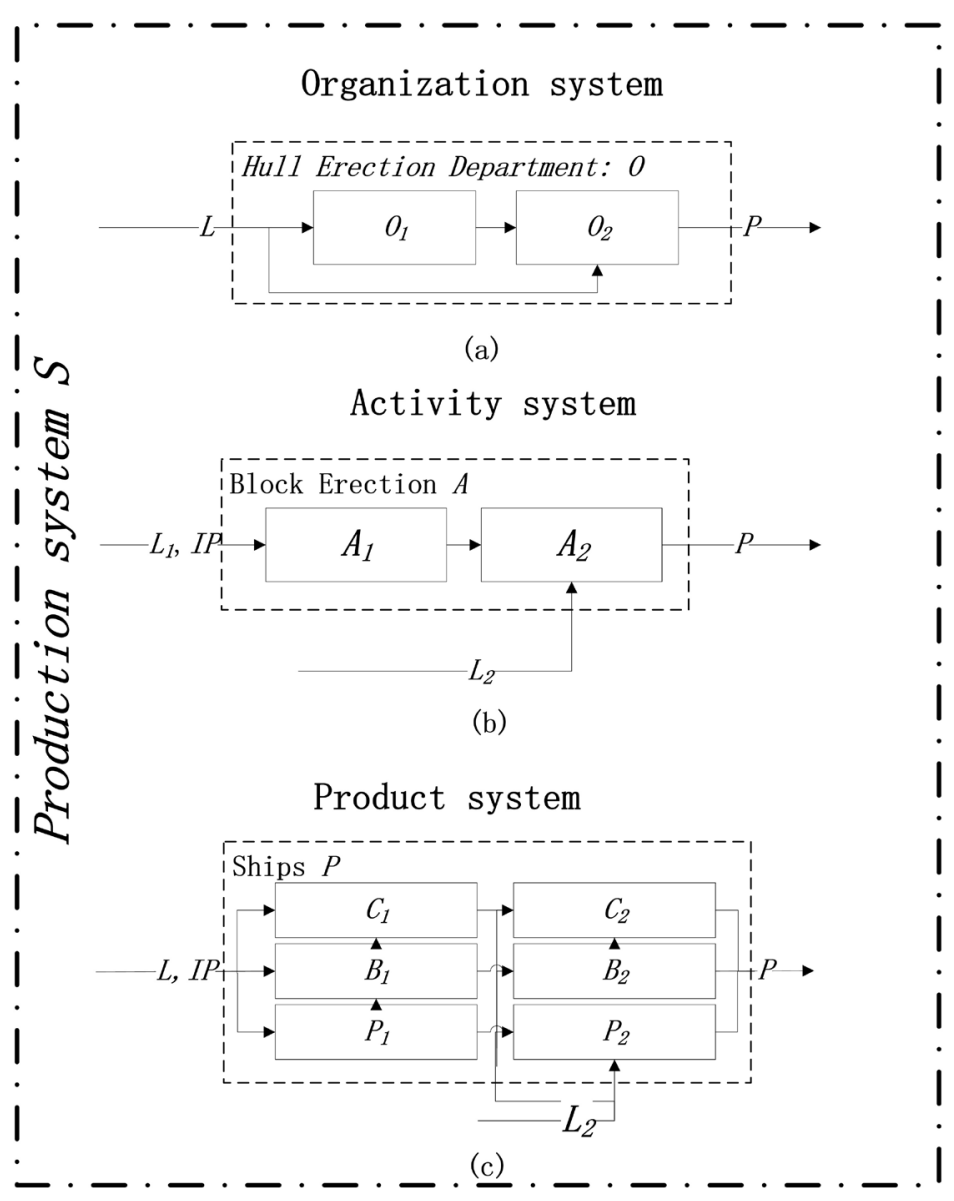

$O_{1} \quad$ Block Pre-erection Department

$\mathrm{O}_{2} \quad$ Block Erection Department

$A_{1} \quad$ Pre-erection work

$A_{2} \quad$ Erection work

$C_{0}$ Block of Container Ship

$B_{0}$ Block of Bulk Cargo Carrier

$P_{0} \quad$ Block of Tanker

IP Intermediate Product

$C_{1} \quad$ Pre-erected Block of Container Ship

$B_{1} \quad$ Pre-erected Block of Bulk Cargo Carrier

$P_{1} \quad$ Pre-erected Block of Tanker

$C_{2}$ Erected Block of Container Ship

$B_{2} \quad$ Erected Block of Bulk Cargo Carrier

$P_{2} \quad$ Erected Block of Tanker

$L \quad$ System total labor

$L_{1} \quad$ Manager

$L_{11}$ Pre-erection Manager

$L_{12}$ Erection Manager

$L_{2}$ Worker

$L_{21}$ Pre-erection Worker

$L_{22}$ Erection Worker

$W \quad$ Idle Recourse

$W_{1}$ Idle Recourse of $O_{1}$

$W_{2}$ Idle Recourse of $O_{1}$

Figure 4. Simplified efficiency driver structure of shipbuilding.

Table 2. Variables of input and output.

\begin{tabular}{ccccccccccc}
\hline$I / O$ & $\boldsymbol{S}$ & $\boldsymbol{O}$ & $\boldsymbol{O}_{1}$ & $\boldsymbol{O}_{2}$ & $\boldsymbol{A}$ & $\boldsymbol{A}_{1}$ & $\boldsymbol{A}_{2}$ & $\boldsymbol{P}$ & $\boldsymbol{P}_{1}$ & $\boldsymbol{P}_{2}$ \\
\hline $\boldsymbol{I}$ & $L$ & $L_{1}$ & $L_{11}$ & $L_{12}$ & $L_{2}$ & $L_{21}$ & $L_{22}$ & $L_{2}, B_{0}, C_{0}, P_{0}$ & $L_{21}, B_{0}, C_{0}, P_{0}$ & $L_{22}, B_{1}, C_{1}, P_{1}$ \\
$\boldsymbol{O}$ & $B, C, P$ & $W, P E, A E$ & $W_{1}, P E_{1}, A E_{1}$ & $W_{2}, P E_{2}, A E_{2}$ & $B, C, P$ & $B_{1}, C_{1}, P_{1}$ & $B_{2}, C_{2}, P_{2}$ & $B_{2}, C_{2}, P_{2}$ & $B_{1}$ & $C_{1}$ \\
\hline
\end{tabular}


Table 3. Result of activity, product and management efficiency (Part).

\begin{tabular}{|c|c|c|c|c|c|c|c|c|c|c|}
\hline$j$ & $E$ & $E_{A}$ & $E_{A 1}$ & $E_{A 2}$ & $E_{T}$ & $E_{T 1}$ & $E_{T 2}$ & $E_{O}$ & $E_{O 1}$ & $E_{O 2}$ \\
\hline 1 & 1 & 1 & 1 & 1 & 0 & 0 & 0 & 0.769 & 0.771 & 0.768 \\
\hline 3 & 0.98 & 0.843 & 0.842 & 0.81 & 0.157 & 0.158 & 0.19 & 0.739 & 0.775 & 0.609 \\
\hline 5 & 0.806 & 0.708 & 0.54 & 0.762 & 0.292 & 0.46 & 0.18 & 0.796 & 0.795 & 0.796 \\
\hline 7 & 1 & 1 & 1 & 1 & 0 & 0 & 0 & 0.869 & 0.87 & 0.869 \\
\hline 9 & 1 & 1 & 1 & 1 & 0 & 0 & 0 & 0.829 & 0.865 & 0.768 \\
\hline 11 & 0.945 & 0.908 & 1 & 0.655 & 0.092 & 0 & 0.345 & 0.56 & 0.703 & 0.356 \\
\hline 13 & 0.754 & 0.77 & 0.96 & 0.534 & 0.23 & 0.04 & 0.466 & 0.558 & 0.576 & 0.523 \\
\hline 15 & 0.546 & 0.636 & 0.644 & 0.493 & 0.099 & 0.098 & 0.507 & 0.318 & 0.423 & 0 \\
\hline 17 & 0.546 & 0.618 & 0.587 & 0.466 & 0.382 & 0.413 & 0.516 & 0.5 & 0.499 & 0.501 \\
\hline 19 & 1 & 1 & 1 & 1 & 0 & 0 & 0 & 0.465 & 0.732 & 0 \\
\hline 21 & 0.827 & 0.853 & 0.605 & 0.931 & 0.004 & 0 & 0.069 & 0.487 & 0.46 & 0.656 \\
\hline 23 & 1 & 1 & 1 & 1 & 0 & 0 & 0 & 0.79 & 0.798 & 0.779 \\
\hline 25 & 0.486 & 0.701 & 0.567 & 0.758 & 0.299 & 0.433 & 0.242 & 0.265 & 0.267 & 0.264 \\
\hline 27 & 0.695 & 0.643 & 0.529 & 0.493 & 0.004 & 0 & 0.481 & 0.322 & 0.402 & 0.153 \\
\hline 29 & 0.739 & 0.699 & 0.438 & 1 & -0.030 & 0.137 & 0 & 0.602 & 0.601 & 0.603 \\
\hline 31 & 0.716 & 0.597 & 0.505 & 0.715 & 0.324 & 0.416 & 0.077 & 0.638 & 0.637 & 0.639 \\
\hline 33 & 1 & 1 & 1 & 1 & 0 & 0 & 0 & 0.76 & 0.811 & 0.674 \\
\hline 35 & 0.913 & 0.978 & 0.827 & 0.812 & 0 & 0 & 0.188 & 0.677 & 0.745 & 0.531 \\
\hline
\end{tabular}

curves were drawn according to the efficiency trend function (11) as shown in Figure 5:

$$
\begin{gathered}
E^{j}=\beta_{0}+\beta_{T} E_{T}^{j}+\beta_{A} E_{A}^{j}+\beta_{O} E_{O}^{j}+\varepsilon=-0.250+0.131 E_{P}^{j}+1.189 E_{A}^{j}+0.113 E_{O}^{j} \\
E_{A}^{j}=\beta_{A 0}+\beta_{A 1} E_{A 1}^{j}+\beta_{A 2} E_{A 2}^{j}+\varepsilon_{A}=0.151+0.512 E_{A 1}^{j}+0.357 E_{A 2}^{j} \\
E_{T}^{j}=\beta_{T 0}+\beta_{T 1} E_{T 1}^{j}+\beta_{T 2} E_{T 2}^{j}+\varepsilon_{T}=0.942+0.887 E_{T 1}^{j}+0.880 E_{T 2}^{j} \\
E_{O}^{j}=\beta_{O 0}+\beta_{O 1} E_{O 1}^{j}+\beta_{O 2} E_{O 2}^{j}+\varepsilon_{O}=-0.013+0.693 E_{O 1}^{j}+0.315 E_{O 2}^{j}
\end{gathered}
$$

\subsection{Analysis and Discussions}

\subsubsection{Model validity analysis}

The significance test of the multiple linear regression analysis to the computing results of efficiency of system and subsystem is shown in Table 2, and the analysis result is shown in Table 4. The determination coefficients of the efficiency function (16)-(19) are $0.868,0.887,0.995$, and 0.905 , respectively. The adjusted determination coefficients of the efficiency function (16)-(19) are 0.856, 0.880, 0.995 and 0.899 , respectively, showing that the fitting degree of the regression results of the four functions is better. The $\mathrm{P}$ values of each function are $3.6 \times$ $10^{-14}, 1.3 \times 10^{-38}, 1.4 \times 10^{-17}, 3.0 \times 10^{-13}$ respectively, less than the significant level of 0.05 , indicating that the independent variable has a significant influence on the dependent variable. 


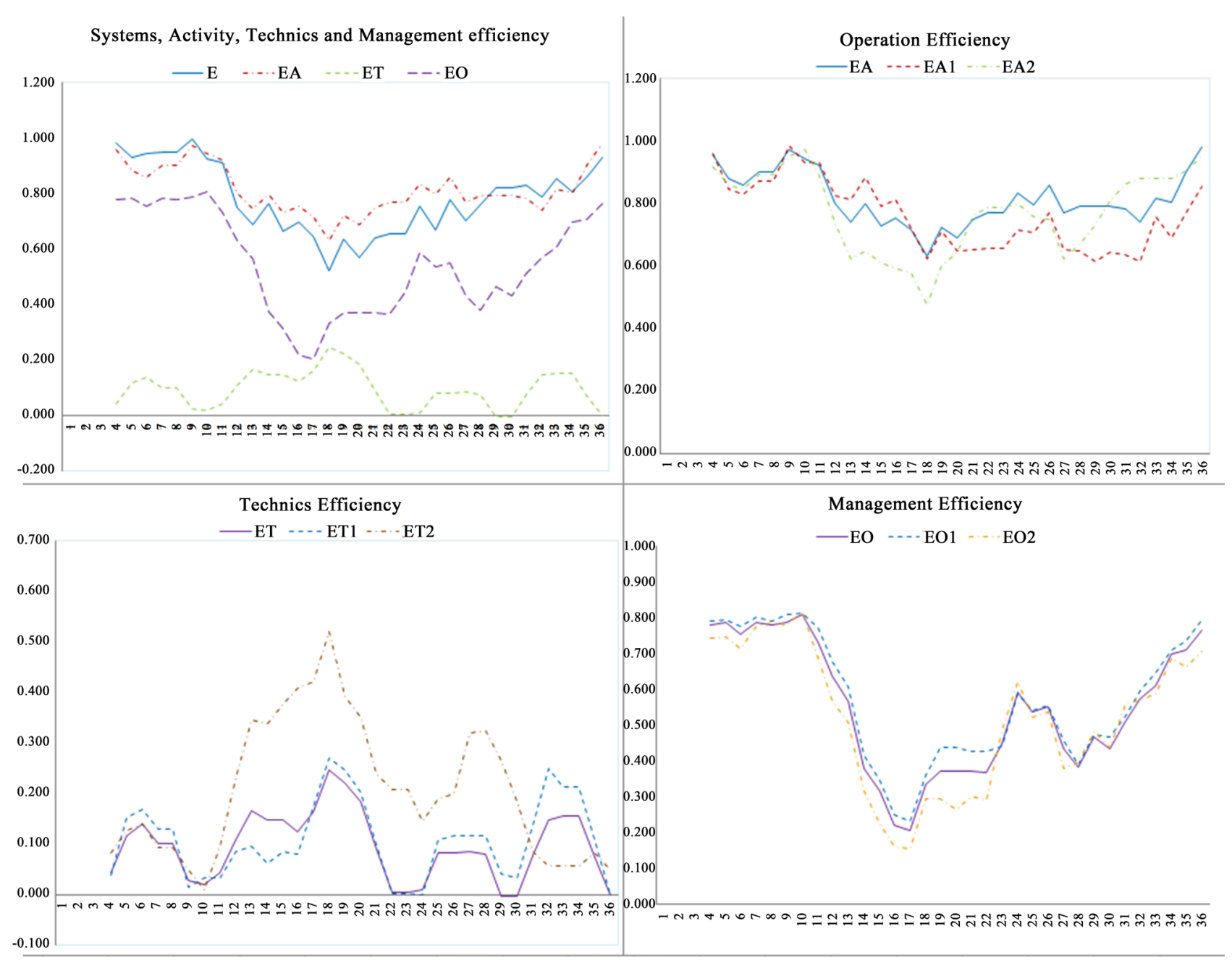

Figure 5. Trend analysis of dimension efficiency.

Table 4. Summary output of regression.

\begin{tabular}{cccc}
\hline Efficiency & R Square & Adjusted R Square & Significance F \\
\hline$E$ & 0.868 & 0.856 & $3.7 \times 10^{-14}$ \\
$E_{O}$ & 0.905 & 0.899 & $1.4 \times 10^{-17}$ \\
$E_{A}$ & 0.887 & 0.880 & $2.3 \times 10^{-16}$ \\
$E_{T}$ & 0.995 & 0.995 & $1.3 \times 10^{-38}$ \\
\hline
\end{tabular}

\subsubsection{Analysis and Discussion}

1) The model decomposes the system efficiency from three dimensions to a number of levels, and a number of internal structure efficiency, which can accurately locate and quantify the inefficient sources within the system. In the example, the system efficiency is divided into 2 levels from 3 dimensions, and 2 subsystems per level, with a total of 9 internal structural efficiencies. The efficiency level of the system is reflected from the one efficiency value, to 9 efficiency values, with two levels and three dimensions. Therefore, it is easier to accurately identify the location of the inefficient sections within the system. Take the re- 
sults of the efficiency during fifth month in Table 3 as an example. The efficiency of the system is 0.806 , showing severe inefficiency. The operation efficiency is 0.780 , the technique efficiency is 0.292 and the management efficiency is 0.796 . All of them are severely inefficient. It also shows that the inefficiency in the technique area is greater, and means there is more room for improvement there. The efficiency of product subsystem 1 is only 0.180 , which means that the technique of product 1 is the main source of technique inefficiency. The efficiency of the two sub subsystems of the process dimension are 0.540 and 0.762 respectively, all of which are severely inefficient. In relative terms, the inefficiency of 1 is greater. The efficiency of the two subsystems of the organizational dimension is 0.795 and 0.796 , respectively, which is about equivalent to the organizational efficiency of 0.796 . This indicates that the management level of the two sub organizations is close, but they are all together in a severely inefficient state.

2) The model can quantitatively describe the contribution of three dimensions of internal structure efficiency to overall system efficiency and the contribution of internal structure efficiency to its upper efficiency structure efficiency via every dimension, so as to provide basis for formulating an efficiency improvement strategy. As shown in Table 5, the operating efficiency of the system efficiency contribution is $1.189,0.131$ respectively and the technique efficiency and management efficiency is 0.113 . The results of 9.1 times and 10.5 times, show that operation efficiency is the main driving factor of the overall system efficiency. The driving effect of technique and management on the efficiency of the system is not significant. The measurement results can indicate a direction for the formulation of efficiency improvement strategies.

3) The model can qualitatively describes the change in the trend of the structural efficiency of each dimension of the observed samples, which provides a basis for judging and predicting the efficiency improvement effects of the corresponding dimensions. From Table 5, we can see that for operation efficiency, the efficiency of process 1 or process 2 is increased by $1 \%$, and the upper operation efficiency is increased by $0.512 \%$ or $0.357 \%$, respectively. The efficiency of operation 1 has more of a driving effect on the upper level of operation efficiency. For the technique and management efficiency, technique efficiency of product 1 or product 2 increased by $1 \%$ the technique efficiency of the upper level system will be increased by $0.678 \%$ or $31 \%$ respectively. As well, the management efficiency of the organization 1 or organization 2 increased by $1 \%$, the management efficiency of the upper level organization will be

Table 5. Contribution degrees of the sub-production systems.

\begin{tabular}{ccccc}
\hline Efficiency & $\beta_{0}$ & $\beta_{1}\left(\beta_{T}\right)$ & $\beta_{2}\left(\beta_{A}\right)$ & $\beta_{O}$ \\
\hline$E$ & -0.250 & 0.131 & 1.189 & 0.113 \\
$E_{T}$ & 0.942 & 0.887 & 0.880 & \\
$E_{A}$ & 0.151 & 0.512 & 0.357 & \\
$E_{O}$ & -0.013 & 0.693 & 0.315 & \\
\hline
\end{tabular}


increased by $0.693 \%$ or $0.131 \%$ respectively. The results show that the efficiency of the pre-erection stage has a greater effect on the system efficiency than that of the erection stage in all of three dimensions. This result verifies that the Chinese theory of improving shipbuilding efficiency by moving the job from the hull erection stage to the block erection stage is correct.

4) The trend curves can dynamically show the relationship between the trend of system efficiency and the trend of internal structure efficiency of each dimension as well as the relationship between the changes of sub-system efficiency and upper system efficiency. It provides a basis for evaluating the effectiveness of efficiency improvement measures. As shown in Figure 5, the internal efficiency of the shipbuilding enterprise is fluctuating in three dimensions, indicating that the internal efficiency of the shipbuilding enterprises is not stable. The enterprise's system efficiency, operation efficiency and management efficiency have shown a significant trend of decline and later of improvement, while the technique efficiency has a dramatic trend of fluctuation. This is because during this period, the enterprise was affected by the external market environment. A decline in that environment led to reduced orders, overcapacity, and increased inefficiency, but after the corresponding measures were taken, the efficiency was improved. The huge fluctuation of the technique efficiency is due to the increase of the new type of ship, and the decrease of the quantity which caused an increase in the difficulty of construction.

Figure 5 also shows the variation trend of the system efficiency as being similar to the operation efficiency, while much different than the technique efficiency. As shown in Figure 5, the variation trend of the system efficiency is similar to the operation efficiency, but much different than the technique efficiency, but between the variation trends of operation efficiency and technique efficiency. It shows that the operation efficiency is the most important driving factor of the overall system efficiency; management efficiency is second, while technique efficiency has little effect on the system efficiency as a whole. In the internal structure efficiency of the three dimensions, the trend of the efficiency of the subsystem of the pre-erection stage is closer to the efficiency of the upper level system. It shows that the previous stage subsystem efficiency has a more driving effect on the efficiency of shipbuilding. This result further confirms that the theory of improving the shipbuilding efficiency by moving the job from hull erection stage to the block erection stage is correct.

5) The model uses window DEA to measure the relative efficiency of subsystems of the same dimension and the same level, and overcomes many problems of efficiency measurement, such as multi input and multi output, multi dimension of input and output, less similar sample units and less sample data.

\section{Conclusion}

The efficiency level and dynamic change within the shipbuilding system are the important basis for judging the effect of the efficiency improvement measures of 
the shipbuilding system. The two-stage efficiency structure analysis model (ESAM) constructed in this paper reflects the internal efficiency of the shipbuilding system from three dimensions of operation, process and management and each dimension with multi levels. ESAM can be sued to reveal the microcosmic sources of system inefficiency; reflect the driving effects of process design, production process and management behavior on the efficiency of the system; analyze the interaction relationship between the structural efficiency and the system efficiency of each dimension and compare the change trends of the structural efficiency of each dimensions and its substructures efficiency.

The empirical analysis of the hull erection process shows that the selected shipbuilding enterprises are generally in a state of serious inefficiency in the internal structure efficiency of the three dimensions, which may imply that most Chinese shipyards are in the same condition. There is even a possibility that they are in worse condition. In internal efficiency, the degree of technique inefficiency and management inefficiency is more serious. The empirical analysis of the hull erection process shows that the case shipyard inner production is in severely inefficient in all the dimensions, which may imply that most Chinese shipyards are in a similar condition. In internal efficiency, the degree of technique inefficiency and management inefficiency is more serious. Management efficiency and operational efficiency show an upward trend, while technique efficiency presents a huge fluctuation with little progress. Therefore, improving management efficiency rather than technique efficiency should be the main direction of improving Chinese shipbuilding efficiency at present.

The case analysis also shows that it is helpful to increase the production efficiency of the shipbuilding production by increasing the amount of jobs in the stage of subsection assembly and reducing the amount of jobs in the stage of closing the carrying stage. Extended to other shipbuilding operations, increasing the jobs in the pre-outfitting stage, corresponding decreasing the jobs in the general assembly stage, are an effective way to improve the production efficiency of outfitting.

\section{Acknowledgements}

This work is supported by grants from the National Natural Science Foundation of China (71372084).

\section{Conflicts of Interest}

The authors declare no conflicts of interest regarding the publication of this paper.

\section{References}

Banker, R. D., Charnes, A., \& Cooper, W. W. (1984). Some Models for Estimating Technical and Scale Inefficiency in Data Envelopment Analysis. Management Science, 30, 1078-1092. https://doi.org/10.1287/mnsc.30.9.1078

Chen, Q. (2002). Complexity and Controlling of Shipbuilding System. Shipbuilding of China, No. 1, 3-9. 
Cheng, C. L., Ren, A. S., \& Wang, Y. C. (2018). Calculation and Convergence of Agricultural Production Efficiency in China Based on the Hicks-Moorsteen Index Method. Jiangsu Agricultural Science, 2, 1-6.

Chudasama, K. M. (2010). Shipbuilding Infrastructure: An Efficiency Analysis of Indian Shipyards. The IUP Journal of Infrastructure, 8, 7-23.

Duan, W. B., \& Yin, X. F. (2009). The Review On China's TFP Research. Nakai Economic Studies, No. 2, 130-140.

Emblemsvag, J. (2014). Lean Project Planning in Shipbuilding. Journal of Ship Production and Design, 30, 79-88. https://doi.org/10.5957/JSPD.30.2.130054

Fafandjel, N., Zamarin, A., \& Hadjina, M. (2010). Shipyard Production Cost Structure Optimisation Model Related to Product Type. International Journal of Production Research, 48, 1479-1491. https://doi.org/10.1080/00207540802609665

Felipe, J. (1999). Total Factor Productivity Growth in East Asia: A Critical Survey. Journal of Development Studies, 35, 1-41. https://doi.org/10.1080/00220389908422579

Gallagher, C. C., Banerjee, S. K., \& Southen, G. (1974). Group Technology in the Shipbuilding Industry. International Journal of Production Research, 12, 45-54. https://doi.org/10.1080/00207547408919539

Hassan, K., \& Kajiwara, H. (2013). Application of Pull Concept-Based Lean Production System in the Ship Building Industry. Journal of Ship Production and Design, 29, 105-116. https://doi.org/10.5957/JSPD.29.3.120021

Jiang, L. P., Bastiansen, E., \& Strandenes, S. P. (2013). The International Competitiveness of China's Shipbuilding Industry. Transportation Research Part E, 60, 39-48. https://doi.org/10.1016/j.tre.2013.10.001

Jin, C. G., Lin, Y., \& Ji, Z. S. (2002). Application of Modern Work Breakdown Structure in Shipbuilding Procedure. Shipbuilding of China, No. 04, 85-89.

Joo, S.-J., \& Choi, H.-C. P. (2015). Assessing Comparative Production Efficiencies for Product Line Management. International Journal of Production Research, 53, 5241-5250. https://doi.org/10.1080/00207543.2015.1015749

Ku, N., Ha, S., \& Roh, M.-I. (2014). Design of Controller for Mobile Robot in Welding Process of Shipbuilding Engineering. Journal of Computational Design and Engineering, 1, 243-255. https://doi.org/10.7315/JCDE.2014.024

Lee, J. S. (2012). An Empirical Analysis for Global Competitiveness of Shipbuilding Industry between Korean and China. Journal of Shipping and Logistics, 28, 385-412. https://doi.org/10.37059/tjosal.2012.28.3.385

Lee, J.-S. (2013). Directions for the Sustainable Development of Korean Small and Medium Sized Shipyards. The Asian Journal of Shipping and Logistics, 29, 335-360. https://doi.org/10.1016/j.ajsl.2013.12.003

Liu, G. X. (2011). Present Situation and Development of Modern Digital Shipbuilding Precision Control Technology. Ship Engineering, 33, 65-68.

Liu, Y. F., Liu, Y. Y., Xu, J. B., \& Lin, Z. D. (2017). Dispersion of Firms' Productivity Change and Efficient Allocation of Labor. China Soft Science Magazine, No. 7, 152-161.

Roh, M.-I., \& Lee, K.-Y. (2010). Optimal Scheduling of Block Lifting in Consideration of the Minimization of Traveling Distance While Unloaded and Wire and Shackle Replacement of a Gantry Crane. Journal of Marine Science Technology, 15, 190-200. https://doi.org/10.1007/s00773-009-0080-3

Tsaur, R.-C., Chen, I.-F., \& Chan, Y.-S. (2017). TFT-LCD Industry Performance Analysis and Evaluation Using GRA and DEA Models. International Journal of Production Research, 55, 4378-4391. https://doi.org/10.1080/00207543.2016.1252863 
Wang, R.-T., Ho, C.-T. B., \& Oh, K. (2010). Measuring Production and Marketing Efficiency Using Grey Relation Analysis and Data Envelopment Analysis. International Journal of Production Research, 48, 183-199. https://doi.org/10.1080/00207540802446803

Zhao, D. G., Liu, J. F., \& Xu, G. M. (2015). Analysis and Countermeasures of Factors Affecting the Production Efficiency of Shipbuilding. Naval Architecture and Ocean Engineering, 31, 74-78.

Zheng, Y. X. (2007). Again Knowledge of Total Factor Productivity. The Journal of Quantitative \& Technical Economics, No. 9, 3-11.

Zhong, H. C., Jiang, R. H., \& Tan, J. H. (2004). Research on Cellular Manufacturing Model and Production Plan Optimum in Shipbuilding. Shipbuilding of China, No. 2, 10-16.

Zhong, Y. G., Xue, K., \& Shi, D. Y. (2014). Clustering and Group Selection of Interim Product in Shipbuilding. Journal of Intelligence Manufacturing, 25, 1393-1401.

https://doi.org/10.1007/s10845-013-0737-y 